\title{
Beyond Survival in AL amyloidosis: Identifying and Satisfying Patients' Needs
}

\author{
Hamza Hassan (D) and Vaishali Sanchorawala *(D)
}

Citation: Hassan, H.;

Sanchorawala, V. Beyond Survival in AL amyloidosis: Identifying and Satisfying Patients' Needs. Hemato 2022, 3, 38-46. https://doi.org/ 10.3390/hemato3010004

Academic Editors: Laurent Garderet, Giovanni Palladini

and Stefan Schönland

Received: 22 November 2021

Accepted: 29 December 2021

Published: 4 January 2022

Publisher's Note: MDPI stays neutral with regard to jurisdictional claims in published maps and institutional affiliations.

Copyright: () 2022 by the authors Licensee MDPI, Basel, Switzerland. This article is an open access article distributed under the terms and conditions of the Creative Commons Attribution (CC BY) license (https:// creativecommons.org/licenses/by/ $4.0 /)$.
Amyloidosis Center, Boston University School of Medicine and Boston Medical Center, Boston, MA 02118, USA; hamza.hassan@bmc.org

* Correspondence: vaishali.sanchorawala@bmc.org

\begin{abstract}
The survivorship needs of patients with light-chain (AL) amyloidosis are complex, as is the diagnosis and treatment itself. Early diagnosis is critical in improving patient outcomes; however, given the nonspecific nature of the symptoms, most patients with AL amyloidosis require evaluation by multiple specialists, resulting in significant delays in diagnosis of up to 3 years. An early and accurate diagnosis can help reduce the psychological toll of the patient's journey to diagnosis. Given the high symptom burden and complex process of diagnosis, it is not surprising that patients with AL amyloidosis report worse health-related quality of life than the general population. Organ dysfunction associated with AL amyloidosis also may make the treatment directed towards plasma cell clone difficult to tolerate, leading to morbidity and mortality. Furthermore, supportive care requires an integrated, multidimensional and patient-centered approach to improve survival and feelings of well-being, as organ responses lag behind hematologic responses. The impact of AL amyloidosis is often devastating for the patient and may last beyond the effects of treatment. Future research is needed to study and assess the needs of survivors of AL amyloidosis utilizing valid, reliable and standardized measures.
\end{abstract}

Keywords: light-chain amyloidosis; survivorship; supportive care; QOL

\section{Introduction}

Millions of adults who survive cancer are relieved when the treatment ends but report a daunting, heavy, and exhausting transition to a new way of life. In 1985, Fitzhugh Mullan highlighted this unmet need, writing "The challenge in overcoming cancer is not only to find therapies that will prevent or arrest the disease quickly, but also to map the middle ground of survivorship and minimize its medical and social hazards" [1]. Much momentum occurred and led to the formation of the National Office of Cancer Survivorship in 1996 by the National Cancer Institute (NCI), in identification of these needs [2]. Cancer survivorship, a distinct phase of the cancer trajectory from diagnosis through the rest of the patient's life, also significantly includes family members, friends, and caregivers. This impetus was continued and reflected on in 'From Cancer Patient to Cancer Survivor: Lost in Transition' [3]. Surviving cancer becomes a chronic illness.

Immunoglobulin light-chain (AL) amyloidosis is a rare disease, with an incidence of 8-12 cases per million persons-years [4]. The prevalence rate has increased due to improved therapies and is estimated as 40-58 patients per million person-years [5]. In the past, median survival was dismal, at 13 months, and further limited to only 6 months among those with advanced cardiac involvement [6,7]. Lack of physician awareness, driven in part by the rarity of this disease, vague overlapping symptoms, non-specific clinical syndromes and lack of effective regulatory agency approved therapies led to delays in accurate diagnosis, causing a significant number of patients to have advanced cardiac involvement at the time of diagnosis.

Until recently, in the absence of approved therapies for AL amyloidosis, off-label multiple myeloma therapies that target the abnormal plasma cells responsible for the 
production of amyloidogenic light-chain precursor proteins were used without much consideration for the underlying organ dysfunction. Thus, these treatments could be associated with significant adverse events, and patients often died before experiencing any benefit [8]. The heterogeneous clinical phenotypes of AL amyloidosis, including cardiovascular, renal, neurologic, and gastrointestinal system manifestations, contribute to morbidity and/or mortality. Depending on the systems involved, the prescribed course, and the response to treatment, patients' experiences vary widely, as does their quality of life, as reported in 'The Patient experience: The Impact of AL amyloidosis' [9].

The natural history longitudinal study of patients with systemic AL amyloidosis demonstrated a steady increase in the median overall survival from 1.4, 2.6, 3.3 to 4.6 years for time periods of 1980-1989, 1990-1999, 2000-2009 and 2010-2019, respectively [10]. Six-month early mortality decreased over time, from $23 \%$ to $13 \%$, during these time periods. Advances in the therapeutic landscape of myeloma led to the transformation of treatments for AL amyloidosis, and yielded a significant increase in life expectancy. The turning point in the landscape was the utilization of high-dose melphalan and stem cell transplant (HDM/SCT) in the early 1990s [11,12], and life expectancy has continued to get better with improved patient selection, better supportive care, and the invention of novel plasma cell targeted therapies [13]. Subsequently, transplant-related mortality (TRM) also declined from $17 \%$ in 1994-2003 to 4\% in 2004-2011 [14]. Thus, HDM/SCT has led to a long-term survival of 20 years or more for $-30 \%$ of patients with AL amyloidosis [15]. New therapeutics for AL amyloidosis were investigated at an accelerated tempo after 2010, including bortezomib-based regimens, ixazomib an oral proteasome inhibitor, next-generation immunomodulatory drugs, and anti-CD38 monoclonal antibodies [16-22]. Many of these also granted long-term disease control in the relapsed/refractory setting [23,24]. By virtue of these advancements, individuals with AL amyloidosis are living longer. Hence, patients can develop long-term complications and diseases of aging, unrelated to AL amyloidosis [10].

Survivorship beyond treatment is substantially important in a rare and multisystem disease such as AL amyloidosis. It is essential that supportive care interventions are developed to ensure that patients' quality of life (QOL) and functional status is maximized, as they live longer with the chronic burdens of their therapies and disease, which affects multiple organs. The long-term outcomes of survival, disease progression, functional outcomes, fertility, and QOL, and the long-term complications of secondary malignancies, are important to focus on during survivorship.

\section{Road to Diagnosis}

Symptoms of AL amyloidosis are often vague and nonspecific. Furthermore, the clinical syndromes of AL amyloidosis vary, and depend on the extent and number of organs affected. Depending on the clinical phenotype, patients report early symptoms of fatigue, dyspnea, lower extremity edema, diarrhea, difficulty swallowing, joint stiffness, carpal tunnel syndrome and dizziness. Diagnosis is often delayed due to overlapping symptoms with other illnesses, and 'knowing something was wrong' is reported to be a mutual feeling among patients [8,9]. Consequently, an early and accurate diagnosis is challenging. In patients' journey to diagnosis, one study identified two themes (A) barriers to an early diagnosis; and (B) the emotional toll of the journey with a delay in diagnosis, particularly in patients with primary cardiac involvement [8]. The road to diagnosis can be rocky and complicated.

In a patient survey conducted by the Amyloidosis Research Consortium (ARC), 63\% of patients experienced a delay in diagnosis of $\geq 6$ months, $48.6 \%$ were evaluated by $>4$ different doctors, and hematologists/oncologists were the most likely (34\%) to make the diagnosis [25]. Patients describe the emotional impact of diagnosis, which often includes experiencing fear, anxiety, and depression [26]. Patients also expressed relief at receiving the ultimate diagnosis because of the anxiety and uncertainty they felt beforehand. A shorter time from initial patient-reported symptom onset to diagnosis is associated with improved survival, emphasizes importance of early diagnosis [27]. It is of pivotal impor- 
tance to educate subspeciality providers as well as primary care physicians to suspect AL amyloidosis with overlapping characteristic cardiac, rheumatologic, renal, dermatologic, neurologic and gastrointestinal manifestations, especially in the presence of monoclonal gammopathy. Red flag symptoms of AL amyloidosis in patients with myeloma should be accurately recognized in the event of coexistence. Prompt referral to multi-disciplinary specialty centers should be considered if convenient to the patient.

\section{Hematologic Response and Organ Response}

Current therapies target the plasma cell dyscrasia and the goals of therapy are to reduce the production of the precursor protein. The objectives of treatment are to achieve as deep a hematologic response as possible, as quickly as possible, followed by an organ response [28]. A deep and durable hematologic response is the goal of therapy in AL amyloidosis [29]. It is imperative to note that the organ responses can lag behind the hematologic response by 6-12 months and can continue to gradually occur many years after treatment $[30,31]$. Organ responses are more likely to be seen in patients that achieve a hematologic complete response (CR), and both hematologic and organ responses are predictors for overall survival in AL amyloidosis [31]. Moreover, higher organ response rates are reported in patients who achieve minimal residual disease (MRD) negativity, and persistent MRD can likely explain persistent organ dysfunction, especially if patients achieve a CR that is not accompanied by an organ response [32,33]. The kinetics of organ response following hematologic response are not well understood. As reported by two large studies, $~ 80 \%$ of renal and cardiac responses occur within 12 months of treatment [30,31]. Despite the high rates of hematologic and organ response to first-line therapy, the disease often recurs, potentially leading to worsening organ function as a result of continued amyloid deposition. Increasing proteinuria and/or worsening renal function after successful treatment always raise the possibility of recurrent amyloidosis, but hematologic relapse is not always obvious. A subset of patients have renal/cardiac progression with normal monoclonal free light chain levels or after achievement of a very good partial hematologic response. In these cases, it is not clear if there is a small amount of circulating amyloidogenic light chain below the detection level or if the worsening of renal/cardiac disease represents the progression of the original, irreversible organ damage.

The institution of additional therapy directed towards plasma cell dyscrasia should weigh the risks and benefits and follow a complete recovery from the toxicities of the first-line therapy. It should not be instituted solely for organ progression in the setting of an adequate hematologic response ( $\geq$ VGPR), unless indicated by other measures and individualized.

In view of the lag in organ response after the hematologic response, patients need to be managed with supportive care until the organs recover completely. Organ dysfunction and lack of organ response can lead to fatigue, extreme weakness, weight loss, edema and congestive heart failure. In addition, lack of appetite, altered taste, nausea, postural dizziness, and shortness of breath are experienced by many patients, even after the completion of treatment, until organ responses occur [34].

\section{Health-Related Quality of Life}

Understanding the patient experience, including the physical and mental aspects of health-related QOL, can help to characterize the burden of disease [35]. QOL is deeply, strongly and broadly affected in AL amyloidosis due to multisystem involvement [34]. Multiple patient testimonials, qualitative interviews with clinicians, quantitative observational studies, and systematic literature reviews have established the broad and significant impact of AL amyloidosis and current treatment on QOL. In 2015, a conceptual model of AL amyloidosis provided an overview of the symptoms associated with AL amyloidosis by organ involvement, showed the treatment's impacts on patient functioning and wellbeing, and showed how the proximal impacts of disease influence patient functioning and QOL [36]. The impact of AL amyloidosis on QOL ranges from impairments of physical 
function to emotional distress, including impairments in mobility, work, sleep, participation in family activities and social relationships, and mental health functioning.

The use of QOL assessments at every physician visit or treatment might provide valuable insights for the treatment of AL amyloidosis. Beyond survival, attention should be given to holistically meeting patients' and caregivers' needs [26]. These include the identification and management of disease- and therapy-specific side effects, as well as interventions to lessen the burden of the emotional distress. Understanding the burden of AL amyloidosis highlights the need for early diagnosis and the unmet need for services and research geared towards improving patients' functioning, well-being, and overall health-related QOL [35].

A recent study that analyzed the safety and efficacy of Daratumumab (Dara) in combination with bortezomib, cyclophosphamide and dexamethasone (VCd) in AL amyloidosis also evaluated patient-reported outcomes as secondary and exploratory endpoints (PRO). These were assessed by European Organization for Research and Treatment of Cancer Quality of Life Questionnaire Core 30-item (EORTC QLQ-C30), the EuroQoL 5-dimensional descriptive system (EQ-5D-5L), Short Form-36 (SF-36), global health status (GHS) and fatigue scale scores. Preliminary reports have shown a clinically shortened median time to improvement and longer median time to worsening for EORTC QLQ-C30 GHS, EQ-5D-5L and fatigue scales in Dara-VCd group as compared to VCd over the initial six cycles. After six cycles, patients in the Dara-VCd group reported continued improvements in mean GHS and fatigue scores while undergoing treatment [37].

\section{Burden of Illness: Symptoms of Disease versus Side Effects of Treatment}

Studies have demonstrated a high symptom burden and low QOL among patients with an AL amyloidosis. Research examining the impact of AL amyloidosis and its treatments on QOL has been limited. Treatment has a major impact on QOL because the rigorous therapeutic regimens are difficult for patients to tolerate. There is an unmet need to develop treatments that not only halt disease progression but also reverse organ damage and improve QOL, without the often-debilitating side effects of existing therapies. Evidence from cross-sectional studies in AL amyloidosis shows broad deficits in functioning and well-being in both treatment-naïve patients and heterogeneous groups of patients with varied disease severity and treatment history $[35,38,39]$. Only one study has reported longitudinal assessments of QOL and the results indicated that greater preand post-treatment QOL, as measured by the SF- $36^{\circledR}$ Health Survey (SF-36), is associated with a reduced risk of mortality among patients who received HDM/SCT treatment [38]. Given the functional burden that AL amyloidosis may place on patients, understanding QOL is of great value to patients. Patient-centered treatment approaches that monitor QOL and symptom burden can foster better communication and treatment decisions between healthcare providers and their patients. Furthermore, examining the impact of treatments on QOL in both the short- and long-term may help to characterize the overall effectiveness of specific treatment regimens.

The burden of therapy is often more difficult to tolerate than the disease burden [35]. Half of patients report that treatment was difficult to tolerate, and treatment did not substantially improve quality of life in $32 \%$ of patients [8]. Beyond prolonging survival, patients wonder about the 'Finish-Line', as the completion of therapy does not yield a prompt resolution of symptoms and return to normalcy. Therapeutic options can contribute to toxicities and patients often succumb to lasting side effects that frequently enhance disease symptoms. Patients often find it difficult to distinguish between symptoms of the disease and the side effects of treatments. This affects the perceived benefits of treatment, as well as the ability to complete the prescribed course of therapy. The risk of treatment-related toxicity may have implications for treatment decisions, adherence, and health-related QOL.

The symptoms of disease and side effects of treatment that commonly overlap include fatigue, diarrhea, edema, weight loss, dysgeusia, sleep disturbances, GI upset, "fogginess", dizziness, tingling and numbness of feet and hands and decreased exercise tolerance. 
Patients also report an impact on their relationship with their spouse, as one spouse turns into a caregiver for the other, particularly during treatment [40]. This hampers the physical, social, and emotional aspects of life, and adds to frustration, anxiety and depression in a disease that can be like a zebra without stripes at presentation [41].

\section{Organ Transplantation for Organ Failure}

Severe organ impairment and dysfunction can lead to organ failure in AL amyloidosis, despite treatment and control of the underlying clone. Organ failure leads to the impairment of health-related QOL as well as the tolerability of plasma cell dyscrasia-targeted treatment. Frequently, organ failure necessitates the need for organ transplantation. There are no clear guidelines regarding eligibility for kidney or heart transplantation in AL amyloidosis. This is, in part, due to the risk of graft failure, recurrence of amyloidosis in the graft, extrarenal or extracardiac organ deterioration and paucity of donor organs. The outcomes of renal and heart transplantation have improved, especially in the presence of hematologic response, as per recent reports. The long-term immunosuppression following solid-organ transplant adds to the risk of cumulative toxicities [42,43].

\section{Fertility after Treatment}

Fertility is usually compromised in patients with AL amyloidosis and of child-bearing age. This could be related to the gonadal toxicity of the treatment leading to premature gonadal dysfunction, erectile dysfunction related to autonomic neuropathy associated with the disease, or immunomodulatory agents leading to teratogenicity. Male and female fertility has not been robustly investigated and addressed in patients with AL amyloidosis.

\section{Secondary Malignancies after Treatment}

The data on secondary malignancies in AL amyloidosis are limited and variable. The long-term outcome of patients treated in clinical trials of immunomodulatory agents for AL amyloidosis reported invasive second primary malignancy in $7 / 125$ patients, which included chronic myelogenous leukemia, myelodysplastic syndrome and solid tumors such as lung cancer, prostate cancer, breast cancer, ovarian cancer, and squamous cell head and neck cancer. The incidence of secondary primary malignancy was $5.6 \%$ in this pooled analysis [44]. Moreover, the overall risk of myelodysplasia is $10 \%$ in transplant-ineligible patients with AL amyloidosis who are treated with prolonged exposure to alkylating agents [45]. The actuarial risk of development of myelodysplasia at 10 years was 18\%, with a median time to development of either myelodysplasia or acute non-lymphocytic leukemia of 58 months (range 14-144) [45]. In comparison, in multiple myeloma, the cumulative 5-year incidence of second solid primary malignancies was $3.8 \%$ in patients who received lenalidomide and 3.4\% in those that did not, (hazard ratio (HR) 1.1, $p=0.72$ ), and the cumulative incidence of second hematologic primary malignancies was $3.1 \%$ and $1.4 \%$, respectively (HR 3.8; $p=0.029$ ). Exposure to lenalidomide plus oral melphalan significantly increased second hematologic primary malignancy risk as compared to melphalan alone (HR 4.86, $p<0.0001$ ) [46]. Recent studies have not reported any acute leukemia or secondary myelodysplasia if maximum number of oral melphalan cycles are limited to nine [47]. The risk of malignancy after SCT for AL amyloidosis is not well reported in studies. One report suggested three cases of malignancy (bladder, lung and metastatic adenocarcinoma, with one case each) in 421 patients undergoing SCT for AL amyloidosis [48].

\section{Causes of Death}

A 40-year longitudinal natural history study from Boston University Amyloidosis Center elaborated on the spectrum of the primary causes of death across the disease course (Figure 1). Cardiac failure and sudden death accounted for $36 \%$ of late-occurring deaths ( $>5$ years), and $66 \%$ of early-occurring deaths ( $\leq 6$ months) [10]. Meanwhile, renal failure emerged as an important cause of late-occurring deaths, indicating the potential lasting effects of this disease and its therapies. In long-term survivors, more deaths were also 
associated with environmental and patient risk factors, such as infections and solid tumor malignancies. With a longer prospective analysis, these non-cardiac causes of death may be found to be even more prominent. Nonetheless, the majority of deaths captured in this study were directly related to AL amyloidosis. Even among long-term survivors, the progression of amyloid organ dysfunction was a common issue. Despite the high proportion of AL amyloidosis-related deaths, there was a significant decline over time. In the latest era, of 2010-2019, 16\% of deaths were from disease-unrelated causes, compared to $3 \%$ in the first era, of 1980-1989. More disease-unrelated deaths are likely to be captured with longer prospective observation. This has the potential to create competing risks in conventional survival analysis, leading to an overestimation of disease risk. Adopting cause-specific frameworks for the survival assessment of AL amyloidosis may be beneficial in the future [10].

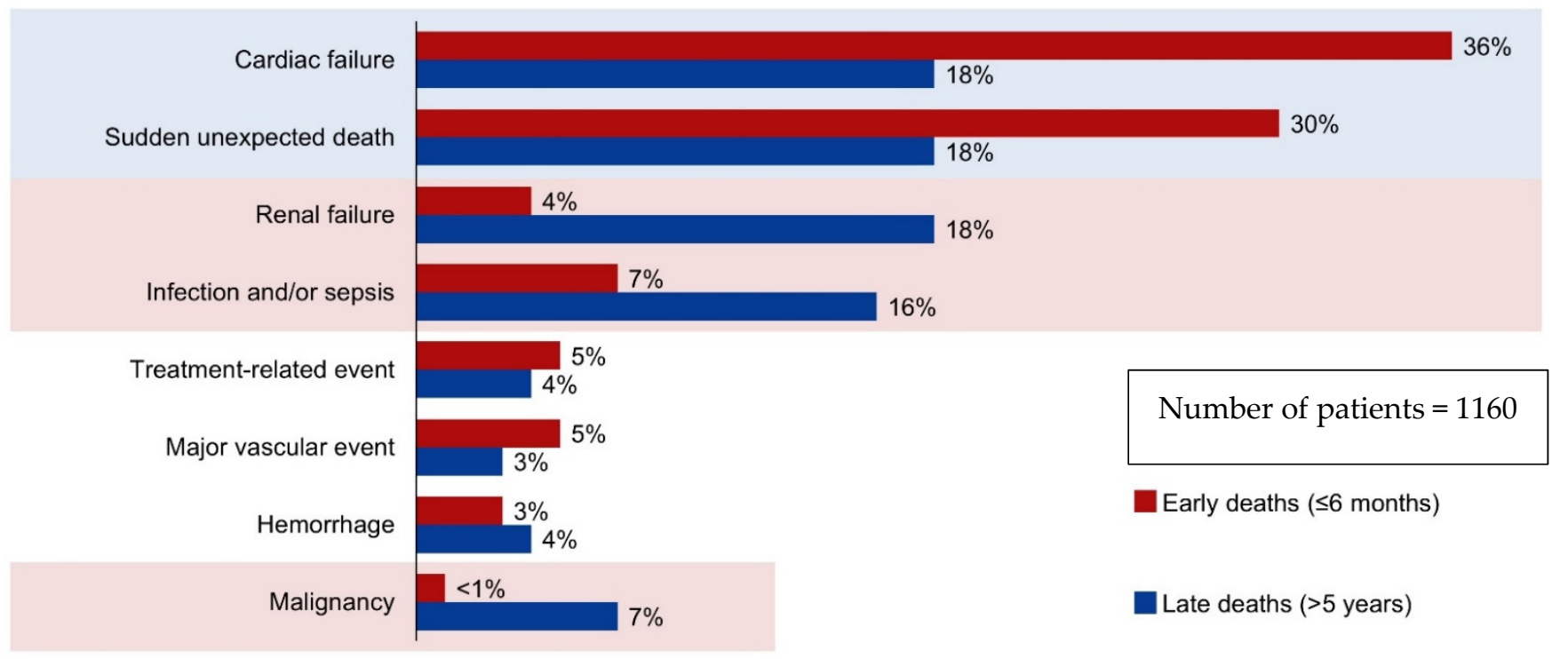

Figure 1. Causes of early and late deaths in a longitudinal natural history study [10].

Collectively, these results indicate that these patients may require a longer follow-up and more detailed inspection for possible malignancies. Further studies should define other longitudinal risk factors, such as smoking or previous treatments, which may impose additional risks.

\section{Conclusions}

Systemic AL amyloidosis has lasting effects on patients' lives. Although a few survivors gain a renewed sense of life and purpose, the toll of both the disease and its treatment on functioning and general well-being makes them wonder what will come next and the location of the finish line. Patients face new problems, new feelings, changes in support, and different ways of looking at the world. Fear of recurrence, role disruption, follow-up medical care, residual effects of therapy, risks of secondary malignancies, economic and psychosocial consequences form major disruptions; a survivor's healthcare is forever altered. Surviving amyloidosis becomes a chronic illness. Early diagnosis, research focused on quality of life with different therapies, and a close partnership between physicians, patients and regulatory divisions will help to identify and satisfy patients' needs, beyond survival.

Author Contributions: Conceptualization, H.H. and V.S.; writing-original draft preparation, H.H.; writing — review and editing, V.S.; supervision, V.S. All authors have read and agreed to the published version of the manuscript.

Funding: Amyloid Research Fund at Boston University School of Medicine. 
Institutional Review Board Statement: Not applicable.

Informed Consent Statement: Not applicable.

Data Availability Statement: Not applicable.

Acknowledgments: We acknowledge the efforts of all the members of the multidisciplinary team of Amyloidosis Center at Boston University School of Medicine and Boston Medical Center. We are thankful to Andrew Staron for providing the figure from the publication by Staron et al.

Conflicts of Interest: The authors declare no conflict of interest.

\section{References}

1. Mullan, F. Seasons of survival: Reflections of a physician with cancer. N. Engl. J. Med. 1985, 313, 270-273. [CrossRef]

2. The National Coalition for Cancer Survivorship. History of the National Coalition for Cancer Survivorship. Available online: https:/ / canceradvocacy.org/about/our-history/ (accessed on 29 October 2021).

3. Hewitt, M.; Greenfield, S.; Stovall, E. From Cancer Patient to Cancer Survivor: Lost in Transition; National Academies Press: Washington, DC, USA, 2005.

4. Kyle, R.A.; Larson, D.R.; Kurtin, P.J.; Kumar, S.; Cerhan, J.R.; Therneau, T.M.; Rajkumar, S.V.; Vachon, C.M.; Dispenzieri, A. Incidence of AL Amyloidosis in Olmsted County, Minnesota, 1990 through 2015. Mayo Clin. Proc. 2019, 94, 465-471. [CrossRef]

5. Quock, T.P.; Yan, T.; Chang, E.; Guthrie, S.; Broder, M.S. Epidemiology of AL amyloidosis: A real-world study using US claims data. Blood Adv. 2018, 2, 1046-1053. [CrossRef]

6. Kyle, R.A.; Greipp, P.R. Amyloidosis (AL). Clinical and laboratory features in 229 cases. Mayo Clin. Proc. 1983, 58, 665-683.

7. Skinner, M.; Anderson, J.; Simms, R.; Falk, R.; Wang, M.; Libbey, C.; Jones, L.A.; Cohen, A.S. Treatment of 100 patients with primary amyloidosis: A randomized trial of melphalan, prednisone, and colchicine versus colchicine only. Am. J. Med. 1996, 100, 290-298. [CrossRef]

8. McCausland, K.L.; White, M.K.; Guthrie, S.D.; Quock, T.; Finkel, M.; Lousada, I.; Bayliss, M.S. Light Chain (AL) Amyloidosis: The Journey to Diagnosis. Patient 2018, 11, 207-216. [CrossRef]

9. Lousada, I.; Boedicker, M. The Impact of AL Amyloidosis: The Patient Experience. Hematol. Oncol. Clin. N. Am. 2020, 34, 1193-1203. [CrossRef]

10. Staron, A.; Zheng, L.; Doros, G.; Connors, L.H.; Mendelson, L.M.; Joshi, T.; Sanchorawala, V. Marked progress in AL amyloidosis survival: A 40-year longitudinal natural history study. Blood Cancer J. 2021, 11, 139. [CrossRef]

11. Comenzo, R.L.; Vosburgh, E.; Simms, R.W.; Bergethon, P.; Sarnacki, D.; Finn, K.; Dubrey, S.; Faller, D.V.; Wright, D.G.; Falk, R.H.; et al. Dose-intensive melphalan with blood stem cell support for the treatment of AL amyloidosis: One-year follow-up in five patients. Blood 1996, 88, 2801-2806. [CrossRef]

12. Skinner, M.; Sanchorawala, V.; Seldin, D.C.; Dember, L.M.; Falk, R.H.; Berk, J.L.; Anderson, J.J.; O’Hara, C.; Finn, K.T.; Libbey, C.A.; et al. High-dose melphalan and autologous stem-cell transplantation in patients with AL amyloidosis: An 8-year study. Ann. Intern. Med. 2004, 140, 85-93. [CrossRef]

13. D’Souza, A.; Dispenzieri, A.; Wirk, B.; Zhang, M.J.; Huang, J.; Gertz, M.A.; Kyle, R.A.; Kumar, S.; Comenzo, R.L.; Peter Gale, R.; et al. Improved Outcomes After Autologous Hematopoietic Cell Transplantation for Light Chain Amyloidosis: A Center for International Blood and Marrow Transplant Research Study. J. Clin. Oncol. 2015, 33, 3741-3749. [CrossRef] [PubMed]

14. Tsai, S.B.; Seldin, D.C.; Quillen, K.; Berk, J.L.; Ruberg, F.L.; Meier-Ewert, H.; Sloan, J.M.; Doros, G.; Finn, K.T.; Skinner, M.; et al. High-dose melphalan and stem cell transplantation for patients with AL amyloidosis: Trends in treatment-related mortality over the past 17 years at a single referral center. Blood 2012, 120, 4445-4446. [CrossRef]

15. Sanchorawala, V.; Sun, F.; Quillen, K.; Sloan, J.M.; Berk, J.L.; Seldin, D.C. Long-term outcome of patients with AL amyloidosis treated with high-dose melphalan and stem cell transplantation: 20-year experience. Blood 2015, 126, 2345-2347. [CrossRef]

16. Mikhael, J.R.; Schuster, S.R.; Jimenez-Zepeda, V.H.; Bello, N.; Spong, J.; Reeder, C.B.; Stewart, A.K.; Bergsagel, P.L.; Fonseca, R. Cyclophosphamide-bortezomib-dexamethasone (CyBorD) produces rapid and complete hematologic response in patients with AL amyloidosis. Blood 2012, 119, 4391-4394. [CrossRef]

17. Palladini, G.; Sachchithanantham, S.; Milani, P.; Gillmore, J.; Foli, A.; Lachmann, H.; Basset, M.; Hawkins, P.; Merlini, G.; Wechalekar, A.D. A European collaborative study of cyclophosphamide, bortezomib, and dexamethasone in upfront treatment of systemic AL amyloidosis. Blood J. Am. Soc. Hematol. 2015, 126, 612-615. [CrossRef]

18. Sanchorawala, V.; Palladini, G.; Kukreti, V.; Zonder, J.A.; Cohen, A.D.; Seldin, D.C.; Dispenzieri, A.; Jaccard, A.; Schönland, S.O.; Berg, D.; et al. A phase $1 / 2$ study of the oral proteasome inhibitor ixazomib in relapsed or refractory AL amyloidosis. Blood 2017, 130, 597-605. [CrossRef]

19. Sanchorawala, V.; Shelton, A.C.; Lo, S.; Varga, C.; Sloan, J.M.; Seldin, D.C. Pomalidomide and dexamethasone in the treatment of AL amyloidosis: Results of a phase 1 and 2 trial. Blood 2016, 128, 1059-1062. [CrossRef]

20. Kaufman, G.P.; Schrier, S.L.; Lafayette, R.A.; Arai, S.; Witteles, R.M.; Liedtke, M. Daratumumab yields rapid and deep hematologic responses in patients with heavily pretreated AL amyloidosis. Blood 2017, 130, 900-902. [CrossRef] 
21. Sanchorawala, V.; Sarosiek, S.; Schulman, A.; Mistark, M.; Migre, M.E.; Cruz, R.; Sloan, J.M.; Brauneis, D.; Shelton, A.C. Safety, tolerability, and response rates of daratumumab in relapsed AL amyloidosis: Results of a phase 2 study. Blood 2020, 135, 1541-1547. [CrossRef]

22. Dispenzieri, A.; Buadi, F.; Laumann, K.; LaPlant, B.; Hayman, S.R.; Kumar, S.K.; Dingli, D.; Zeldenrust, S.R.; Mikhael, J.R.; Hall, R.; et al. Activity of pomalidomide in patients with immunoglobulin light-chain amyloidosis. Blood 2012, 119, 5397-5404. [CrossRef]

23. Hassan, H.; Anwer, F.; Javaid, A.; Hashmi, H. Progress in research: Daratumumab improves treatment outcomes of patients with AL amyloidosis. Crit. Rev. Oncol. Hematol. 2021, 165, 103435. [CrossRef]

24. Sarosiek, S.; Sanchorawala, V. Treatment Options For Relapsed/refractory Systemic Light-Chain (AL) Amyloidosis: Current Perspectives. J. Blood Med. 2019, 10, 373-380. [CrossRef]

25. Lousada, I.; Comenzo, R.L.; Landau, H.; Guthrie, S.; Merlini, G. Light Chain Amyloidosis: Patient Experience Survey from the Amyloidosis Research Consortium. Adv. Ther. 2015, 32, 920-928. [CrossRef]

26. Shu, J.; Lo, S.; Phillips, M.; Sun, F.; Seldin, D.C.; Berenbaum, I.; Berk, J.L.; Sanchorawala, V. Depression and anxiety in patients with AL amyloidosis as assessed by the SF-36 questionnaire: Experience in 1226 patients. Amyloid 2016, 23, 188-193. [CrossRef]

27. Schulman, A.; Connors, L.H.; Weinberg, J.; Mendelson, L.M.; Joshi, T.; Shelton, A.C.; Sanchorawala, V. Patient outcomes in light chain (AL) amyloidosis: The clock is ticking from symptoms to diagnosis. Eur. J. Haematol. 2020, 105, 495-501. [CrossRef]

28. Sanchorawala, V. High-dose melphalan and autologous peripheral blood stem cell transplantation in AL amyloidosis. Acta Haematol. 2020, 143, 381-387. [CrossRef]

29. Palladini, G.; Schönland, S.O.; Sanchorawala, V.; Kumar, S.; Wechalekar, A.; Hegenbart, U.; Milani, P.; Ando, Y.; Westermark, P.; Dispenzieri, A.; et al. Clarification on the definition of complete haematologic response in light-chain (AL) amyloidosis. Amyloid 2021, 28, 1-2. [CrossRef]

30. Kaufman, G.P.; Dispenzieri, A.; Gertz, M.A.; Lacy, M.Q.; Buadi, F.K.; Hayman, S.R.; Leung, N.; Dingli, D.; Lust, J.A.; Lin, Y.; et al. Kinetics of organ response and survival following normalization of the serum free light chain ratio in AL amyloidosis. Am. $J$. Hematol. 2015, 90, 181-186. [CrossRef]

31. Szalat, R.; Sarosiek, S.; Havasi, A.; Brauneis, D.; Sloan, J.M.; Sanchorawala, V. Organ responses after highdose melphalan and stemcell transplantation in AL amyloidosis. Leukemia 2021, 35, 916-919. [CrossRef]

32. Palladini, G.; Paiva, B.; Wechalekar, A.; Massa, M.; Milani, P.; Lasa, M.; Ravichandran, S.; Krsnik, I.; Basset, M.; Burgos, L. Minimal residual disease negativity by next-generation flow cytometry is associated with improved organ response in AL amyloidosis. Blood Cancer J. 2021, 11, 34. [CrossRef]

33. Staron, A.; Burks, E.J.; Lee, J.C.; Sarosiek, S.; Sloan, J.M.; Sanchorawala, V. Assessment of minimal residual disease using multiparametric flow cytometry in patients with AL amyloidosis. Blood Adv. 2020, 4, 880-884. [CrossRef] [PubMed]

34. Merlini, G.; Dispenzieri, A.; Sanchorawala, V.; Schönland, S.O.; Palladini, G.; Hawkins, P.N.; Gertz, M.A. Systemic immunoglobulin light chain amyloidosis. Nat. Rev. Dis. Primers 2018, 4, 38. [CrossRef]

35. Bayliss, M.; McCausland, K.L.; Guthrie, S.D.; White, M.K. The burden of amyloid light chain amyloidosis on health-related quality of life. Orphanet J. Rare Dis. 2017, 12, 15. [CrossRef]

36. Lin, H.M.; Gao, X.; Cooke, C.E.; Berg, D.; Labotka, R.; Faller, D.V.; Seal, B.; Hari, P. Disease burden of systemic light-chain amyloidosis: A systematic literature review. Curr. Med. Res. Opin. 2017, 33, 1017-1031. [CrossRef]

37. Sanchorawala, V.; Palladini, G.; Minnema, M.C.; Jaccard, A.; Lee, H.C.; Gibbs, S.D.; Mollee, P.; Venner, C.P.; Lu, J.; Schönland, S.; et al. Health-Related Quality of Life in Patients with AL Amyloidosis Treated with Daratumumab, Bortezomib, Cyclophosphamide, and Dexamethasone: Results from the Phase 3 Andromeda Study. Blood 2020, 136, 37-40. [CrossRef]

38. Seldin, D.C.; Anderson, J.J.; Sanchorawala, V.; Malek, K.; Wright, D.G.; Quillen, K.; Finn, K.T.; Berk, J.L.; Dember, L.M.; Falk, R.H.; et al. Improvement in quality of life of patients with AL amyloidosis treated with high-dose melphalan and autologous stem cell transplantation. Blood 2004, 104, 1888-1893. [CrossRef]

39. Caccialanza, R.; Palladini, G.; Klersy, C.; Cereda, E.; Bonardi, C.; Cameletti, B.; Montagna, E.; Russo, P.; Foli, A.; Milani, P. Nutritional status independently affects quality of life of patients with systemic immunoglobulin light-chain (AL) amyloidosis. Ann. Hematol. 2012, 91, 399-406. [CrossRef]

40. Lin, H.M.; Seldin, D.; Hui, A.-M.; Berg, D.; Dietrich, C.N.; Flood, E. The patient's perspective on the symptom and everyday life impact of AL amyloidosis. Amyloid 2015, 22, 244-251. [CrossRef]

41. Staron, A.; Kataria, Y.; Murray, D.L.; Sloan, J.M.; Sanchorawala, V. Systemic AL amyloidosis with an undetectable plasma cell dyscrasia: A zebra without stripes. Am. J. Hematol. 2020, 95, E45-E48. [CrossRef] [PubMed]

42. Angel-Korman, A.; Stern, L.; Sarosiek, S.; Sloan, J.M.; Doros, G.; Sanchorawala, V.; Havasi, A. Long-term outcome of kidney transplantation in AL amyloidosis. Kidney Int. 2019, 95, 405-411. [CrossRef]

43. Grogan, M.; Gertz, M.; McCurdy, A.; Roeker, L.; Kyle, R.; Kushwaha, S.; Daly, R.; Dearani, J.; Rodeheffer, R.; Frantz, R.; et al. Long term outcomes of cardiac transplant for immunoglobulin light chain amyloidosis: The Mayo Clinic experience. World J. Transplant. 2016, 6, 380-388. [CrossRef]

44. Sanchorawala, V.; Doros, G.; Shelton, A.C. Long term outcome of patients treated on clinical trials of immunomodulatory agents for the treatment of immunoglobulin light chain (AL) amyloidosis: A pooled analysis. Am. J. Hematol. 2019, 94, E194-E196. [CrossRef] 
45. Gertz, M.A.; Lacy, M.Q.; Lust, J.A.; Greipp, P.R.; Witzig, T.E.; Kyle, R.A. Long-term risk of myelodysplasia in melphalan-treated patients with immunoglobulin light-chain amyloidosis. Haematologica 2008, 93, 1402-1406. [CrossRef]

46. Palumbo, A.; Bringhen, S.; Kumar, S.K.; Lupparelli, G.; Usmani, S.; Waage, A.; Larocca, A.; van der Holt, B.; Musto, P.; Offidani, M. Second primary malignancies with lenalidomide therapy for newly diagnosed myeloma: A meta-analysis of individual patient data. Lancet Oncol. 2014, 15, 333-342. [CrossRef]

47. Kastritis, E.; Leleu, X.; Arnulf, B.; Zamagni, E.; Cibeira, M.T.; Kwok, F.; Mollee, P.; Hájek, R.; Moreau, P.; Jaccard, A. Bortezomib, melphalan, and dexamethasone for light-chain amyloidosis. J. Clin. Oncol. 2020, 38, 3252-3260. [CrossRef]

48. Cibeira, M.T.; Sanchorawala, V.; Seldin, D.C.; Quillen, K.; Berk, J.L.; Dember, L.M.; Segal, A.; Ruberg, F.; Meier-Ewert, H.; Andrea, N.T.; et al. Outcome of AL amyloidosis after high-dose melphalan and autologous stem cell transplantation: Long-term results in a series of 421 patients. Blood 2011, 118, 4346-4352. [CrossRef] 